\title{
The effect of long-term feeding of conjugated linoleic acid on fertility in Japanese quail
}

\author{
R. Aydin", M. Karaman, H.H.C. Toprak, A.K. Ozugur, D. Aydin and T. Cicek \\ Department of Animal Science, Kahramanmaras Sutcu Imam University, 46060 Kahramanmaras, Turkey
}

\begin{abstract}
The objective of this study was to determine the effects of the long-term feeding of conjugated linoleic acid (CLA) on laying hen performance, egg fertility and hatchability of fertile eggs of Japanese quail (Coturnix coturnix japonica). One hundred and sixty 7-day old Japanese quail chicks were randomly assigned to four groups (40 birds per group) and fed for five weeks on a commercial diet supplemented with either 0.5\% hazelnut (Group A), 0.5\% sunflower oil (Group B), 0.25\% CLA (Group C) or 0.5\% CLA (Group D). The birds received water and feed ad libitum during the study. At the end of the five weeks the birds were sexed, and 21 females and seven males from each group were selected. For a further six weeks these selected birds were fed a layer diet supplemented with their respective sources of oil. Eggs were collected daily and incubated weekly. The fertility rate was determined by visual inspection at the end of the incubation period. Dietary CLA at the inclusion level of $0.5 \%$, but not at $0.25 \%$, caused a significant decrease in percentage hatchability of the fertile eggs compared to Groups A and B. Hatchability of fertile eggs from Groups A, B, C and D was 74, 80, 72 and 70, respectively. Fertility rates between Groups A, B, C and $\mathrm{D}$ did not differ significantly, and were 64.4, 56.4, 66.0 and 62.8\%, respectively. Hen-day egg production of Groups A, C and D were similar, but in weeks 3, 4, 5 and 6, hens in Group B had a significantly lower hen-day egg production (\%) compared to Group A. Also, in weeks 3, 4, 5 and 6, egg size in Group B was significantly lower than that in the other groups. From this study it is concluded that dietary CLA at inclusion levels of $0.25 \%$ or $0.5 \%$ did not influence egg fertility, egg weight and egg production in Japanese quail.
\end{abstract}

Keywords: Conjugated linoleic acid, fertility rate, laying performance, Japanese quail

\#Corresponding author. E-mail: rahimaydin@ksu.edu.tr

\section{Introduction}

Conjugated linoleic acids, known as CLA, are a group of polyunsaturated fatty acids (PUFA) produced as a result of bacterial biohydrogenation in the rumen. Therefore, meat and dairy products from ruminants are primary sources of CLA isomers. Cis-9, trans-11 (c-9, t-11) and trans-10, cis-12 (t-10, c-12) CLA isomers are the main isomers in commercially synthesized CLA, while the c-9, t-11 CLA isomer is the predominant CLA in meat and dairy products (Chin et al., 1992). Interest in using CLA in animal feeds to enrich food composition has grown since several beneficial biological properties related to human health have been shown in animal studies. Some of the important biological properties of CLA are anticarcinogenic (Belury, 2002), antiatherogenic (Lee et al., 1994, Wilson et al., 2000) and antidiabetic (Houseknecht et al., 1998) actions. Feeding CLA has also been shown to decrease fat deposition and therefore increase the percentage of lean muscle in growing pigs (Ostrowska et al., 1999). It has been reported that the c-9, t-11 CLA isomer is associated with the anticarcinogenic properties of CLA and the t-10, c-12 CLA isomer with its effects on lipid metabolism and body composition (Pariza et al., 2001).

Chicken eggs were reported to contain as much as $11 \%$ CLA through the feeding of a diet supplemented with 5\% CLA to laying hens (Chamruspollert \& Sell, 1999). In an experiment conducted by Chamruspollert \& Sell (1999), the rate of egg production was not affected by any level of CLA in chicken diets. In the same experiment it was found that the average weight of the eggs and yolk decreased in the treatment where the hens received a diet containing 5\% CLA. However, in a second experiment, the feeding of the 5\% CLA diet over a period of 36 days did not affect rate of egg production and egg weight (Chamruspollert \& Sell, 1999).

The effects of dietary CLA on the hatchability of fertile eggs have been studied extensively in the chicken and Japanese quail (Coturnix coturnix japonica) (Aydin et al., 2001; Aydin \& Cook, 2004). It was 
observed that dietary CLA caused adverse effects on hatchability when the CLA was included in a low-fat diet. In one study it was shown that CLA at a level of $0.5 \%$ in the diet caused complete embryonic mortality in fertile chicken eggs (Aydin et al., 2001). Another study conducted on Japanese quails showed that embryonic mortality would ensue, depending on the CLA dose and duration of feeding the diets supplemented with CLA (Aydin \& Cook, 2004). It was concluded that embryonic mortality occurred in the eggs because of the modification of the fatty acid composition of the egg yolk due to a low ratio of unsaturated (UFA) to saturated fatty acids (SFA).

Use of high levels of CLA supplementation in diets has been shown to have adverse effects on layer performance such as egg production and egg weight in chickens. It was reported that, with increasing levels of CLA $(0,1,2,3,4,5$, or $6 \%)$ in the diet, egg production, egg weight and feed efficiency decreased linearly (Shang et al., 2004). Another study showed that dietary CLA caused a significant decrease in egg production even when included at a level of $0.5 \%$ (Jones et al., 2000). However, a study conducted with Japanese quail showed that dietary CLA influenced egg production and fatty acid composition of egg yolk in a dose- and time-dependent mode (Aydin \& Cook, 2004). It was also reported that the inclusion of CLA in a diet at a level of $2 \%$ and higher affected egg weight significantly compared to a control group. Previous data suggested that the inclusion of CLA in the diets of chickens vs. Japanese quails affected fatty acid composition and egg fertility parameters differently.

The objective of this study was to investigate the effects of CLA-supplemented diets on egg fertility rate, hatchability of fertile eggs and hen-day egg production in the Japanese quail.

\section{Materials and Methods}

One hundred and sixty one-day old male and female Japanese quail chicks were housed at the experimental farm station of the Faculty of Agriculture at the Kahramanmaras Sutcu Imam University, Turkey. Twenty four hours light per day was applied and the birds received a starter diet and water ad libitum. At seven days of age, the chicks were randomly assigned to four treatment groups of 40 birds each and were fed for five weeks on a grower diet supplemented with either $0.5 \%$ hazelnut oil (Group A, Control), 0.5\% sunflower oil (Group B), 0.25\% CLA (Group C) or 0.5\% CLA (Group D). The CLA source contained $60 \%$ CLA. Calculated chemical composition of the commercial grower diet ( $/ \mathrm{kg})$ was: Dry matter $-880 \mathrm{~g}$; crude protein - $200 \mathrm{~g}$; crude fibre $-60 \mathrm{~g}$; ash $-80 \mathrm{~g}$; $\mathrm{NaCl}-3.5 \mathrm{~g}$; calcium - $15 \mathrm{~g}$; total phosphorus - $6.5 \mathrm{~g}$; lysine - 10 g; methionine - 4.0 g; cysteine - 3.5 g; metabolisable energy - 12.97 MJ; vitamin A - 8000 IU; vitamin $\mathrm{D}_{3}-800 \mathrm{IU}$; vitamin $\mathrm{E}-15 \mathrm{mg}$; vitamin $\mathrm{K}_{3}-2 \mathrm{mg}$; manganese - $60 \mathrm{mg}$ and zinc - $40 \mathrm{mg}$. Feed and water were supplied ad libitum. At the end of the first five weeks of the study, the sex of the birds was determined, and 21 females and seven males were selected from each treatment. For the next six weeks a commercial layer diet supplemented at the same levels of oil as during the first period were fed ad libitum to the respective groups. Calculated chemical composition of the layer diet $(/ \mathrm{kg})$ was: Dry matter $-880 \mathrm{~g}$; crude protein - $160 \mathrm{~g}$; crude fibre - $70 \mathrm{~g}$; ash $-130 \mathrm{~g}$; $\mathrm{NaCl}$ - $3.5 \mathrm{~g}$; calcium - $30 \mathrm{~g}$; total phosphorus - $10 \mathrm{~g}$; lysine - 7 g; methionine - 3.3 g; cysteine - 3.1 g; metabolisable energy - $11.3 \mathrm{MJ}$; vitamin A - $8000 \mathrm{IU}$; vitamin D 1500 IU; riboflavin - 4 mg; cobalamine - 10 mg; vitamin E - 15 mg; vitamin K - 2 mg; choline - 500 mg; niacin - $25 \mathrm{mg}$; manganese - $60 \mathrm{mg}$ and zinc - $50 \mathrm{mg}$. It was calculated that all diets (except Diet C) used in both the growing and laying stages were isoenergetic and isonitrogenous. Daily photoperiod was 15 hours during the laying period.

Egg production and total egg weights were recorded daily. Eggs were collected daily and kept at room temperature for one week, and then incubated. At the end of the incubation period, all unhatched eggs were broken and their content examined to determine their state of fertility (\%). The hatchability (\%) was computed as a percentage of total fertile eggs that hatched during each week.

Prior to statistical analyses, the hatchability of fertile eggs and fertility values were transformed to arcsine of their square roots. All data for laying performance and egg weights were subjected to analysis of variance in a general linear model (SPSS software 10.0; Chicago, IL). Mean values for the groups were compared by using the Tukey test (SPSS software 10.0; Chicago, IL). Differences were considered significant at the level of $\mathrm{P}<0.05$.

\section{Results}

Table 1 presents the effects of dietary oils and CLA on egg production in Japanese quails. For the first two weeks of the laying period there was no significant difference between treatments for hen-day egg 
production. Dietary CLA at levels of 0.25 and $0.5 \%$ did not influence egg production (\%) negatively compared to the control group. However, after the first two weeks the quails receiving the diet containing $0.5 \%$ sunflower oil (Diet B) had a lower $(\mathrm{P}<0.05$ ) level of egg production compared to the control.

Table 1 The effects of diets ${ }^{1}$ supplemented with $0.5 \%$ hazelnut oil, $0.5 \%$ sunflower oil, $0.25 \%$ CLA or $0.5 \%$ CLA on the egg production (\%) of Japanese quail

\begin{tabular}{crrrr}
\hline \multirow{2}{*}{ Weeks } & \multicolumn{4}{c}{ Egg production (Means \pm s.e.) } \\
\cline { 2 - 5 } & \multicolumn{1}{c}{ Group A } & \multicolumn{1}{c}{ Group B } & \multicolumn{1}{c}{ Group C } & \multicolumn{1}{c}{ Group D } \\
\hline 1 & $32.38 \pm 3.89$ & $31.74 \pm 2.59$ & $31.00 \pm 3.63$ & $26.67 \pm 2.91$ \\
2 & $72.02 \pm 1.97$ & $70.83 \pm 1.44$ & $74.38 \pm 2.47$ & $70.83 \pm 2.26$ \\
3 & $92.52^{\mathrm{a}} \pm 0.87$ & $77.55^{\mathrm{b}} \pm 1.29$ & $86.28^{\mathrm{ab}} \pm 1.01$ & $88.44^{\mathrm{ab}} \pm 1.10$ \\
4 & $83.67^{\mathrm{ab}} \pm 1.03$ & $76.87^{\mathrm{b}} \pm 1.00$ & $90.85^{\mathrm{a}} \pm 1.12$ & $84.35^{\mathrm{ab}} \pm 0.94$ \\
5 & $92.14^{\mathrm{a}} \pm 0.91$ & $85.00^{\mathrm{b}} \pm 1.00$ & $92.43^{\mathrm{a}} \pm 0.80$ & $90.00^{\mathrm{ab}} \pm 0.58$ \\
6 & $94.29^{\mathrm{a}} \pm 0.64$ & $83.57^{\mathrm{b}} \pm 0.68$ & $94.11^{\mathrm{a}} \pm 0.84$ & $90.00^{\mathrm{ab}} \pm 1.09$ \\
\hline
\end{tabular}

${ }^{1}$ Diets were fed ad libitum

Group A - basal diet plus 0.5\% hazelnut oil; Group B - basal diet plus 0.5\% sunflower oil; Group C - basal diet plus $0.25 \%$ CLA; Group D - basal diet plus 0.5\% CLA-60

${ }^{\mathrm{a}, \mathrm{b}}$ Means within a row lacking a common superscript differ $(\mathrm{P}<0.05)$

Table 2 The effect of diets ${ }^{1}$ supplemented with $0.5 \%$ hazelnut oil, $0.5 \%$ sunflower oil, $0.25 \%$ CLA or $0.5 \%$ CLA on the average weight of eggs (g) of Japanese quail

\begin{tabular}{crrrr}
\hline \multirow{2}{*}{ Weeks } & \multicolumn{4}{c}{ Egg weights (Means \pm s.e.) } \\
\cline { 2 - 5 } & \multicolumn{1}{c}{ Group A } & \multicolumn{1}{c}{ Group B } & \multicolumn{1}{c}{ Group C } & \multicolumn{1}{c}{ Group D } \\
\hline 1 & $9.20 \pm 0.05$ & $9.65 \pm 0.04$ & $9.08 \pm 0.03$ & $9.86 \pm 0.08$ \\
2 & $10.59 \pm 0.01$ & $10.84 \pm 0.01$ & $10.50 \pm 0.01$ & $10.85 \pm 0.01$ \\
3 & $11.19^{\mathrm{b}} \pm 0.01$ & $11.09^{\mathrm{b}} \pm 0.01$ & $11.19^{\mathrm{b}} \pm 0.01$ & $11.67^{\mathrm{a}} \pm 0.01$ \\
4 & $11.79^{\mathrm{ab}} \pm 0.01$ & $11.44^{\mathrm{b}} \pm 0.01$ & $11.44^{\mathrm{b}} \pm 0.01$ & $11.92^{\mathrm{a}} \pm 0.01$ \\
5 & $11.76^{\mathrm{a}} \pm 0.01$ & $11.37^{\mathrm{b}} \pm 0.01$ & $11.62^{\mathrm{ab}} \pm 0.01$ & $11.82^{\mathrm{a}} \pm 0.01$ \\
6 & $11.70^{\mathrm{a}} \pm 0.01$ & $11.40^{\mathrm{b}} \pm 0.01$ & $11.52^{\mathrm{ab}} \pm 0.01$ & $11.64^{\mathrm{ab}} \pm 0.01$ \\
\hline
\end{tabular}

\footnotetext{
${ }^{1}$ Diets were fed ad libitum

Group A - basal diet plus 0.5\% hazelnut oil; Group B - basal diet plus 0.5\% sunflower oil; Group C - basal diet plus $0.25 \%$ CLA; Group D - basal diet plus 0.5\% CLA-60

${ }^{\mathrm{a}, \mathrm{b}}$ Means within a row lacking a common superscript differ $(\mathrm{P}<0.05)$
}

The effects of including oils or different levels of CLA in the diets of quails on their average egg weights are shown in Table 2. For the first two weeks of the laying period there were no significant differences in egg weight between groups. However, from the third to the sixth week of the laying period the individual weight of the eggs from Group B was lower $(\mathrm{P}<0.05)$ than that of Group A. Dietary CLA at $0.25 \%$ and $0.5 \%$ inclusion did not influence egg weights, compared to Group A.

Figure 1 presents the effects of dietary oils and CLA on the percentage hatchability of fertile eggs. Overall, hatchability of the fertile eggs from Group D was significantly lower than that of Groups A and B. 
Hatchability of the fertile eggs from Groups A, B, C and D was 74, 80, 72 and 70\%, respectively, and did not differ between Groups A, B or C.

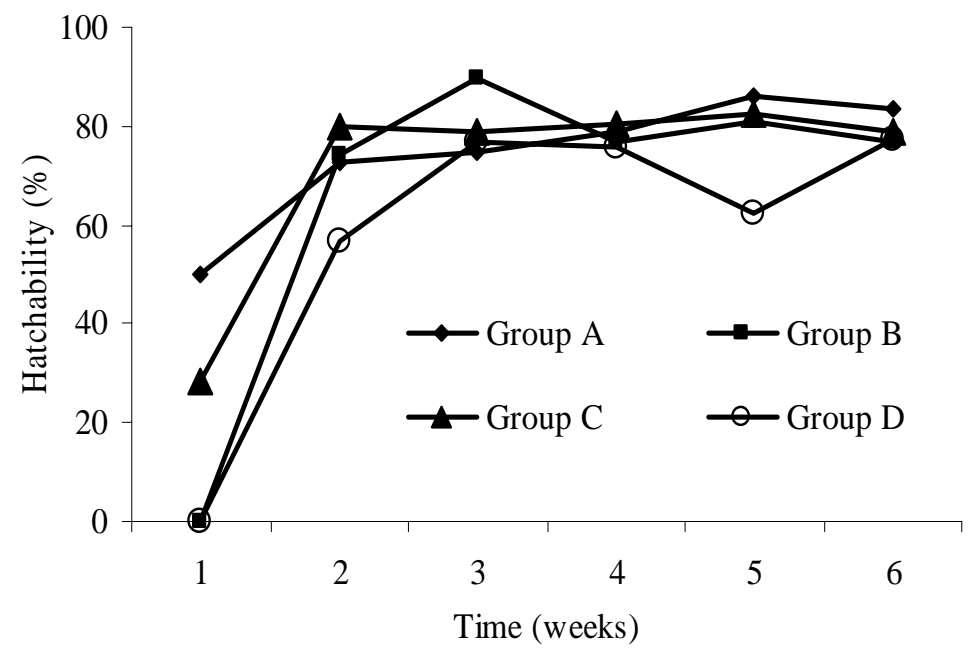

Figure 1 The effects of diets ${ }^{1}$ supplemented with $0.5 \%$ hazelnut oil, $0.5 \%$ sunflower oil, $0.25 \%$ CLA or $0.5 \%$ CLA on the hatchability of fertile Japanese quail eggs

${ }^{1}$ Diets were fed ad libitum for six weeks. Dietary treatments: Group A - basal diet plus $0.5 \%$ hazelnut oil; Group B - basal diet plus 0.5\% sunflower oil; Group C - basal diet plus 0.25\% CLA; Group D - basal diet plus $0.5 \%$ CLA-60

The effects of dietary oils and CLA on egg fertility are shown in Figure 2. Fertility rate in the groups reached optimal levels after four weeks of feeding. The inclusion of $0.25 \%$ and $0.5 \%$ CLA in the diet did not influence fertility rate adversely. There were no significant differences in fertility rate between Groups A, B, $\mathrm{C}$ and $\mathrm{D}$, and were on average for the six weeks $64.4,56.4,66.0$ and $62.8 \%$, respectively.

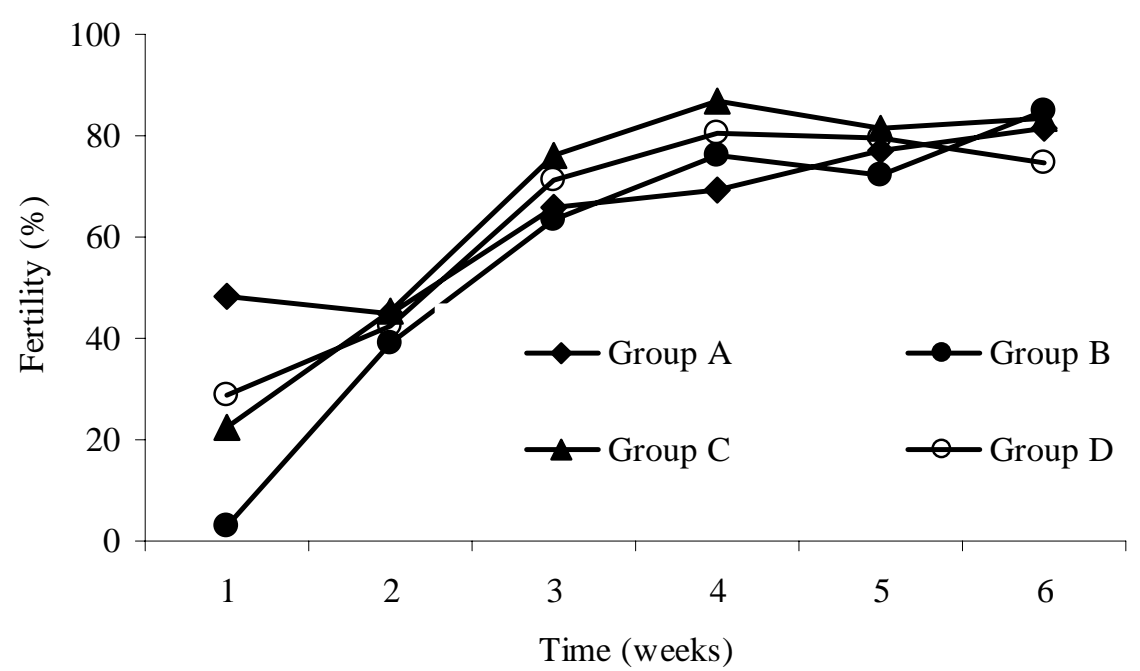

Figure 2 The effects of diets ${ }^{1}$ supplemented with $0.5 \%$ hazelnut oil, $0.5 \%$ sunflower oil, $0.25 \%$ CLA or $0.5 \%$ CLA on the fertility of Japanese quail eggs

${ }^{1}$ Diets were fed ad libitum for six weeks. Dietary treatments: Group A - basal diet plus 0.5\% hazelnut oil; Group B - basal diet plus 0.5\% sunflower oil; Group C - basal diet plus 0.25\% CLA; Group D - basal diet plus $0.5 \%$ CLA- 60 


\section{Discussion}

There are conflicting results concerning the effects of dietary CLA on the laying performance of chickens. It was reported that increasing levels of dietary CLA $(0,1,2,3,4,5$ or 6\%) decreased egg production, egg weight and feed efficiency in chickens linearly (Shang et al., 2004). However, another study showed that 5\% CLA did not influence egg production in chickens (Chamruspollert \& Sell, 1999) but average weight of eggs and yolks decreased in the hens receiving the 5\% CLA diet (Chamruspollert \& Sell, 1999). However, in a second experiment of the same study, it was observed that, over 36 days, feeding a $5 \%$ CLA diet did not affect rate of egg production or egg weight. In another investigation it was shown that dietary CLA caused a significant reduction in egg production at a level of inclusion as low as 0.5\% CLA (Jones et al., 2000), while Raes et al. (2002) reported that a diet containing 1\% CLA did not influence egg weight or laying rate in chickens. In a study conducted with Japanese quail, dietary CLA was shown to influence egg production and fatty acid composition of egg yolk in a dose- and time-dependent mode (Aydin \& Cook, 2004). It was also reported that dietary CLA at levels of $2 \%$ and higher affected egg weight significantly compared to the control. Previous data suggested that the inclusion of dietary CLA in chicken and Japanese quail diets affected the fatty acid composition and egg parameters differently between the species. It seems to follow a dose- and time-dependent mode. In the present study dietary CLA at a level of $0.5 \%$ did not influence egg weight or egg production compared to the control. Also, no differences in egg weight and egg production were observed between Group $C$ and the other groups, despite the fact that this treatment did not contain, on a calculated basis, the same concentrations of energy and protein.

Since yolk fat plays a crucial role as a source of energy and essential nutrients in avian embryonic development, significant changes in the fatty acid composition of egg yolk can have adverse side-effects on embryo survival (Donaldson \& Fites, 1970). Dietary CLA was shown to have the potential to induce chick embryonic mortality in a dose- and time-dependent mode by influencing the fatty acid composition of the egg yolk in quails (Aydin \& Cook, 2004). Previously, it was shown that dietary CLA inhibited the stearoylCoA desaturase enzyme (Park et al., 2000), which led to a lower concentration of monounsaturated fatty acids (primarily C18:1, n-9) and higher concentrations of SFA in egg yolk. It was also shown that embryonic mortality observed in fertile eggs from quails fed higher levels of CLA was the result of a higher SFA concentration in the eggs (Aydin \& Cook, 2004). In a previous study, the diets containing 3, 2 and 1\% CLA caused 100\% embryonic mortality after 6, 10 and 12 days of feeding, respectively. During the present study the diet containing $0.25 \%$ CLA did not cause any adverse effects on chick hatchability. However, it was found that overall hatchability (\%) of fertile eggs from the quails fed the 0.5\% CLA diet was lower (P < 0.05 ) than that of those receiving the control and $0.25 \%$ CLA supplemented diets (64 vs. 84 or 86, respectively). Similarly, the diet supplemented with $0.5 \%$ CLA influenced percentage hatchability of fertile eggs significantly ( $\mathrm{P}<0.05$ ), compared to Group $\mathrm{A}$. The average embryonic mortality of $36 \%$ in eggs from Japanese quails receiving the diet containing $0.5 \%$ CLA was less than that found in chickens. This suggests that Japanese quail may be more resistant to adverse effects of CLA than chickens, though the designs of the studies do not allow for direct comparisons (Aydin \& Cook, 2004).

\section{Conclusion}

In light of previous studies, dietary CLA at the higher levels of inclusion significantly influenced hatchability by modifying the fatty acid composition of fertile eggs. The present study showed that dietary CLA at levels of $0.25 \%$ and $0.5 \%$ did not influence fertility rate nor egg weight and egg production (\%) in Japanese quails. To the knowledge of the authors, this is the first study that investigated the effects of dietary CLA on egg fertility rate in Japanese quails. Therefore, more studies are required to evaluate the effects of higher levels of dietary CLA on fertility.

\section{References}

Aydin, R. \& Cook, M.E., 2004. The effect of dietary conjugated linoleic acid on egg yolk fatty acids and hatchability in Japanese quail. Poult. Sci. 83, 2016-2022.

Aydin, R., Pariza, M.W. \& Cook, M.E., 2001. Olive oil prevents the adverse effects of dietary conjugated linoleic acid on chick hatchability and egg quality. J. Nutr. 131, 800-806.

Belury, M.A., 2002. Inhibition of carcinogenesis by conjugated linoleic acid: Potential mechanisms of action. J. Nutr. 132, 2995-2998. 
Chamruspollert, M. \& Sell, J.L., 1999. Transfer of dietary conjugated linoleic acid to egg yolks of chickens. Poult. Sci. 78, 1138-1150.

Chin, S.F., Storkson, J.M., Ha, Y.L. \& Pariza, M.W., 1992. Dietary sources of conjugated dienoic isomers of linoleic acid, a newly recognized class of anti carcinogens. Food Comp. Anal. 5, 185-197.

Donaldson, W.E. \& Fites, B.L., 1970. Embryo mortality in quail induced by cyclopropene fatty acids: reduction by maternal diets high in unsaturated fatty acids. J. Nutr. 100, 605-610.

Houseknecht, K.L., Vanden Heuvel, J.P., Moya-Camarena, S.Y., Portocarrero, C.P., Peck, L.W., Nickel, K.P. \& Belury, M.A., 1998. Dietary conjugated linoleic acid normalizes impaired glucose tolerance in the zucker diabetic fatty rat. Biochem. Biophys. Res. Comm. 244, 678-682.

Jones, S., Ma, D.W.L., Robinson, F.E., Field, C.J. \& Clandinin, M.T., 2000. Isomers of conjugated linoleic acid (CLA) are incorporated into egg yolk lipids by CLA-fed laying hens. J. Nutr. 130, 2002-2005.

Lee, K.N., Kritchevsky, D. \& Pariza, M.W., 1994. Conjugated linoleic acid and atherosclerosis in rabbits. Atherosclerosis 108, 19-25.

Ostrowska, E., Muralithran, M., Cross, R.F., Bauman, D.E. \& Dunshea, F.R., 1999. Dietary conjugated linoleic acids increase lean tissue and decrease fat deposition in growing pigs. J. Nutr. 129, 2037-2042.

Pariza, M.W., Park, Y. \& Cook, M.E., 2001. The biologically active isomers of conjugated linoleic acid. Progr. Lipid Res. 40, 283-298.

Park, Y., Storkson, J.M., Ntambi, J.M., Cook, M.E., Sih, C.J. \& Pariza, M.W., 2000. Inhibition of hepatic stearoyl-CoA desaturase activity by trans-10, cis-12 conjugated linoleic acid and its derivatives. Biochim. Biop. Acta 1486, 285-292.

Raes, K., Huyghebaert, G., Smet, S.D., Nollet, L., Arnouts, S. \& Demeyer, D., 2002. The deposition of conjugated linoleic acids in eggs of laying hens fed diets varying in fat level and fatty acid profile. J. Nutr. 132, 182-189.

Shang, X.G., Wang, F.L., Li, D.F., Yin, J.D. \& Li, J.Y., 2004. Effects of dietary conjugated linoleic acid on the productivity of laying hens and egg quality during refrigerated storage. Poult. Sci. 83, 1688-1695.

Wilson, T.A., Nicolosi, R.J., Chrysam, M. \& Kritchevsky, D., 2000. Conjugated linoleic acid reduces early aortic atherosclerosis greater than linoleic acid in hypercholesterolemic hamsters. Nutr. Res. 20, 17951805. 